九州大学学術情報リポジトリ

Kyushu University Institutional Repository

Introducing Viewpoints of Mechanics into Basic Growth Analysis (1) : Three Aspects of Growth Mechanics compared with Three Law of Motion

Shimojo, Masataka

Faculty of Agriculture, Kyushu University

Ikeda, Kentaro

Faculty of Agriculture, Kyushu University

Asano, Yoki

Employed Research Scientist, Miyazaki University

Ishiwaka, Reiko

Faculty of Agriculture, Kyushu University

他

https://doi.org/10.5109/9243

出版情報：九州大学大学院農学研究院紀要. 51 (2)，pp. 285-287，2006-10-27. Faculty of Agriculture, Kyushu University

バージョン :

権利関係 : 


\title{
Introducing Viewpoints of Mechanics into Basic Growth Analysis - (I) Three Aspects of Growth Mechanics compared with Three Laws of Motion -
}

\author{
Masataka SHIMOJO*, Kentarou IKEDA ${ }^{1}$, Yoki ASANO ${ }^{2}$, Reiko ISHIWAKA ${ }^{3}$, \\ Hiroyuki SATO ${ }^{4}$, Yutaka NAKANO ${ }^{5}$, Manabu TOBISA ${ }^{6}$, Noriko OHBA $^{7}$, \\ Minako EGUCHI ${ }^{8}$ and Yasuhisa MASUDA
}

\author{
Laboratory of Animal Feed Science, Division of Animal Science, Department of Animal \\ and Marine Bioresource Sciences, Faculty of Agriculture, Kyushu University, \\ Fukuoka 812-8581, Japan \\ (Received June 30, 2006 and accepted July 24, 2006)
}

\begin{abstract}
This study was conducted to analyze growth phenomena by introducing mechanical viewpoints into basic growth analysis. Relating weight $(W)$, absolute growth rate (AGR) and growth acceleration (GA) suggested that (AGR) ${ }^{2}$, which was described as the product of $W$ and GA, looked like force involved in the growth of an animal or a plant. This might be due to the resemblance to the second law of Newton's three laws of motion, where the product of mass and acceleration is related with force to an object. If $\mathrm{GA}=0$, then $\mathrm{AGR}=0$. This caused the weight to stop changes and to keep the constant value with the passage of time, showing a resemblance to the law of inertia that is the first one of three laws of motion. AGR was obtained by extracting the square root of $W \square G A$, taking both positive and negative values. Since AGR played the leading part in growth mechanics, $W$ took both positive and negative values. The positive $W$ was the weight of an animal or a plant, and in terms of it the negative $W$ was assumed to be environmental substances from which an animal or a plant was constructed. If the positive AGR was the action of an animal or a plant on the environment, then the negative AGR was the reaction taken by the environment. The sum of positive AGR and negative AGR was equal to zero. This might show a resemblance to the law of action and reaction, the third one of three laws of motion. There were three aspects of growth mechanics that might be compared with Newton's three laws of motion.
\end{abstract}

\section{INTRODUCTION}

Basic growth analysis has long been used for analyzing the macro-process of growth both in ruminants (Brody, 1945) and in forages (Watson, 1952; Radford, 1967; Hunt, 1990). This method is not popular now and replaced often by simulation models, as shown by Milthorpe and Moorby (1979), Parks (1982) and France and Thornley (1984), for example.

Shimojo et al. (2002) reported in a study of basic growth analysis that weight, absolute growth rate and growth acceleration were related by relative growth rate. This was attributed to symmetric properties of exponential function with base $e$ with respect to its differential and definite integral, a mystic beauty of Napier's number ' $e$ '. It is known in mechanics that the use of acceleration is of importance to investigating the

${ }^{1}$ Former Research Fellow, Faculty of Agriculture, Kyushu University

${ }^{2}$ Employed Research Scientist, Miyazaki University, Miyazaki 889-2192, Japan

${ }^{3}$ Research Fellow, Faculty of Agriculture, Kyushu University

${ }^{4}$ Laboratory of Animal Feed Science, Division of Animal Science, Department of Animal and Marine Bioresource Sciences, Graduate School of Bioresource and Bioenvironmental Sciences, Kyushu University

${ }^{5}$ University Farm, Faculty of Agriculture, Kyushu University

${ }^{6}$ Faculty of Agriculture, Miyazaki University, Miyazaki 889-2192, Japan

${ }^{7}$ Research Student, School of Agriculture, Kyushu University

8 Technical Official, School of Agriculture, Kyushu University

* Corresponding author (E-mail: mshimojo@agr.kyushu-u.ac.jp) motion of object. Likewise, growth acceleration might be expected to give mechanical viewpoints to the analysis of growth.

The present study was designed to investigate mechanical aspects of growth by introducing acceleration into basic growth analysis in comparison with Newton's laws of motion.

\section{THREE ASPECTS OF GROWTH MECHANICS COMPARED WITH THREE LAWS OF MOTION}

Weight, relative growth rate, absolute growth rate and growth acceleration in basic growth analysis

In basic growth analysis of a ruminant animal or a forage plant, the following equation is given first when relative growth rate (RGR) is used,

$$
\frac{1}{W} \frac{d W}{d t}=\mathrm{RGR}
$$

where $W=$ weight,$\quad t=$ time.

Then, indefinite integral of equation (1) and determining integration constant gives

$$
W=W_{0} \square \exp (\operatorname{RGR} \square t),
$$

where $W_{0}=$ the weight at $t=0$.

The differentiation of $W$ gives absolute growth rate (AGR),

$$
\begin{aligned}
\operatorname{AGR} & =\frac{d W}{d t} \\
& =\mathrm{RGR} \square W_{0} \square \exp (\operatorname{RGR} \square t) .
\end{aligned}
$$



(GA),

The differentiation of AGR gives growth acceleration

$$
\begin{aligned}
\mathrm{GA} & =\frac{d(\mathrm{AGR})}{d t} \\
& =(\mathrm{RGR})^{2} \square W_{\mathbf{0}} \square \exp (\mathrm{RGR} \square t) .
\end{aligned}
$$

\section{Relationships between $\boldsymbol{W}$, AGR and GA}

Combining equations (2), (3) and (4) gives

$\frac{\mathrm{AGR}}{W}=\frac{\mathrm{GA}}{\mathrm{AGR}}=\mathrm{RGR}$.

Equation (5) shows that RGR is a key to the relationships between three terms, the importance of RGR in basic growth analysis as shown by Shimojo et al. (2002). An aspect that is derived from equation (5) will be taken up in this study.

\section{Aspect derived from equation (5)} by

The aspect that is derived from equation (5) is given

$$
(\mathrm{AGR})^{2}=W \square \mathrm{GA}
$$

The right-hand side of equation (6), the product of $W$ and GA, might show a resemblance to the product of mass and acceleration that is related with force to an object. This is the second law of three laws of motion, namely Newton's equation of motion (Kawabe, 2006) given by

$$
F=m \square a,
$$

where $m=$ mass of an object, $a=$ acceleration, $F=$ force. Comparing equations (6) and (7) suggests that (AGR) ${ }^{2}$ looks like force that gets involved in the growth. This may give a mechanical viewpoint to growth analysis. Therefore, we would like to focus our attention on equation (6) that describes growth force, instead of equation (2) for weight. In other words, the leading part in growth mechanics is changed from $W$ to AGR in this study.

\section{A modified form of equation (6)}

Actually, equation (8), a modified form of equation (6), is taken up from now on,

$$
\mathrm{AGR}= \pm \sqrt{W \square \mathrm{GA}} .
$$

Equation (8) shows not only a positive value but also a negative one for AGR, a mathematical phenomenon that should be accepted.

Rewriting equation (8) gives

$$
\mathrm{AGR}= \pm\left(W_{\mathbf{0}}\right) \square(\mathrm{RGR}) \square \exp (\mathrm{RGR} \square t) .
$$

Equation (9) shows that \pm sign is given to the right-hand side globally. There may also be locally giving, where \pm sign is given to one of the three terms. Changing globally giving to locally giving will lead to mathematical contradictions. However, resolving these contradictions might be expected to give new aspects to growth mechanics.

\section{Locally giving \pm sign to the right-hand side of equation (9)}

There are two different cases when compared to Newton's laws of motion (Kawabe, 2006), namely GA $\neq 0$ and $\mathrm{GA}=0$ for growth mechanics.

(A) $\mathrm{GA} \neq 0$

(A-1) Giving \pm sign to $W_{0}$

This is given by

$$
\operatorname{AGR}=\left( \pm W_{\mathbf{0}}\right) \square(\mathrm{RGR}) \square \exp (\operatorname{RGR} \square t) .
$$

Equation (10) is contradictory to equation (3) because of including $-W_{\mathbf{0}}$, the negative weight that is difficult to explain. However, equation (10) is not discarded from the mathematical viewpoint. Thus, this requires a modification of equation (2) for $W$ as follows,

$$
W=\left( \pm W_{0}\right) \square \exp (\operatorname{RGR} \square t) .
$$

The differentiation of equation (11) gives the same form as that of equation (10), namely

$$
\mathrm{AGR}=\left( \pm W_{\mathbf{0}}\right) \square(\mathrm{RGR}) \square \exp (\operatorname{RGR} \square t) .
$$

This may result in the resolution of the contradiction.

This procedure shows that resolving the contradiction caused by equation (10) requires the existence of negative weight $\left(-W_{0}\right)$ as well as positive weight $\left(+W_{0}\right)$ for weight, a demand coming from mathematical viewpoints.

(A-2) Giving \pm sign to RGR

This is given by

$$
\operatorname{AGR}=\left(W_{0}\right) \square( \pm \mathrm{RGR}) \square \exp (\operatorname{RGR} \square t) .
$$

Equation (13) is contradictory to the principle of differential, namely that of equation (2) for $W$. However, in order to accept equation (13), equation (2) is modified as follows,

$$
W=\left(W_{0}\right) \square \exp (( \pm \mathrm{RGR}) \square t) .
$$

The differentiation of equation (14) gives

$$
\mathrm{AGR}=\left(W_{0}\right) \square( \pm \mathrm{RGR}) \square \exp (( \pm \mathrm{RGR}) \square t) .
$$

This may result in the resolution of contradiction caused by equation (13), though there is a gap in the resolving process.

This procedure shows that resolving the contradiction caused by equation (13) requires weight decrease (-RGR) as well as weight increase (+ RGR), a demand coming from the mathematical viewpoint.

(A-3) Giving \pm sign to $\exp (\operatorname{RGR} \square t)$

This is given by

$$
\operatorname{AGR}=\left(W_{0}\right) \square(\operatorname{RGR}) \square( \pm \exp (\operatorname{RGR} \square t)) .
$$

Equation (16) gives the same phenomenon as that of equation (10) shown in (A-1). This is because, as shown in equation (2) for $W, W_{\mathbf{0}}$ and $\exp (\operatorname{RGR} \square t)$ are related by the product form.

(B) $\mathrm{GA}=0$

Inserting $\mathrm{GA}=0$ into equation (8) for AGR gives

$\mathrm{AGR}= \pm \sqrt{W \square 0}$ 
$=0$.

Thus, inserting AGR = 0 into equations (12) and (15) for AGR gives

$$
\begin{aligned}
& 0=\left( \pm W_{\mathbf{0}}\right) \square(\mathrm{RGR}) \square \exp (\mathrm{RGR} \square t), \\
& 0=\left(W_{\mathbf{0}}\right) \square( \pm \mathrm{RGR}) \square \exp (( \pm \mathrm{RGR}) \square t) .
\end{aligned}
$$

Since $W_{0} \neq 0, \exp (\operatorname{RGR} \square t) \neq 0$ and $\exp (( \pm \mathrm{RGR}) \square t) \neq 0$, RGR is equal to 0 in equations (18) and (19).

Then, inserting RGR $=0$ into equations (11) and (14) for $W$ results in

$$
\begin{aligned}
& W=\left( \pm W_{0}\right) \square \exp (0 \square t) \\
& = \pm W_{0} \text {, } \\
& W=\left(W_{0}\right) \square \exp (( \pm 0) \square t) \\
& =W_{0} \text {. }
\end{aligned}
$$

Equations (20) and (21) show that weight stops changing and keeps a constant value with the passage of time. This might look like the first law of three laws of motion, the law of inertia where object is at rest or keeps a linear motion with constant velocity (Kawabe, 2006).

\section{What are derived from equations (11), (14), (20) and (21) for $W$}

What are derived from equations (11), (14), (20) and (21) for $W$ are

$$
\begin{aligned}
& W_{\mathbf{1}}=\left(W_{\mathbf{0}}\right) \square \exp (\mathrm{RGR} \square t), \\
& W_{\mathbf{2}}=\left(-W_{\mathbf{0}}\right) \square \exp (\mathrm{RGR} \square t) . \\
& W_{\mathbf{3}}=\left(W_{\mathbf{0}}\right) \square \exp ((-\mathrm{RGR}) \square t), \\
& W_{\mathbf{4}}=\left(-W_{\mathbf{0}}\right) \square \exp ((-\mathrm{RGR}) \square t) . \\
& W_{\mathbf{5}}=W_{\mathbf{0}}, \quad W_{\mathbf{6}}=-W_{\mathbf{0}} .
\end{aligned}
$$

What is common to equations (22) (24) is the existence of positive weight $\left(+W_{0}\right)$ and negative weight $\left(-W_{0}\right)$. The positive weight is the weight of an animal or a plant. We attempt to suppose that there occurs, in environment, a negative weight in terms of that of an animal or a plant. This suggests that the body of an animal or of a plant is composed of environmental substances. It is also shown that an animal or a plant has to take environmental substances into the body in order to live or show growth. However, equations (22) (24) do not show the efficiency of utilizing environmental substances with which an animal or a plant grows.

\section{AGRs derived from equations (22) (24)}

AGRs derived from the differentiation of equations (22) $\sim(24)$ are

$$
\mathrm{AGR}_{\mathbf{1}}=\left(W_{\mathbf{0}}\right) \square(\mathrm{RGR}) \square \exp (\mathrm{RGR} \square t),
$$

$$
\begin{aligned}
& \mathrm{AGR}_{2}=\left(-W_{0}\right) \square(\mathrm{RGR}) \square \exp (\mathrm{RGR} \square t) . \\
& \mathrm{AGR}_{3}=\left(W_{0}\right) \square(-\mathrm{RGR}) \square \exp ((-\mathrm{RGR}) \square t), \\
& \mathrm{AGR}_{4}=\left(-W_{0}\right) \square(-\mathrm{RGR}) \square \exp ((-\mathrm{RGR}) \square t) . \\
& \mathrm{AGR}_{5}=0, \quad \mathrm{AGR}_{6}=0 .
\end{aligned}
$$

Therefore, the following is given from equations (25) and (26);

$$
\begin{array}{ll}
\mathrm{AGR}_{1}+\mathrm{AGR}_{2}=0 & \left(\mathrm{AGR}_{1}=-\mathrm{AGR}_{2}\right), \\
\mathrm{AGR}_{3}+\mathrm{AGR}_{4}=0 & \left(\mathrm{AGR}_{3}=-\mathrm{AGR}_{4}\right),
\end{array}
$$

Equations (28) and (29) suggest that there is a direction toward which AGR takes action, where opposite directions are observed between $\mathrm{AGR}_{1}$ and $\mathrm{AGR}_{2}$ and between $\mathrm{AGR}_{3}$ and $\mathrm{AGR}_{4}$. Since AGR is considered to be force for growth, these equations might look like the law of action and reaction, the third one of three laws of motion (Kawabe, 2006). This suggests that the action of an animal or a plant on the environment is accompanied simultaneously by the reaction taken by the environment.

\section{Conclusions}

Introducing mechanical viewpoints into basic growth analysis suggests three aspects of growth mechanics that might be compared with Newton's three laws of motion.

\section{REFERENCES}

Brody, S. 1945 Time relations of growth of individuals and populations. In "Bioenergetics and growth-with special reference to the efficiency complex in domestic animals", Reinhold Publishing Corporation, New York, pp. 484-574

France, J. and J. H. M. Thornley 1984 Growth functions. In "Mathematical Models in Agriculture-A Quantitative Approach to Problems in Agriculture and Related Sciences", Butterworth \& Co (Publishers) Ltd, London, pp. 75-94

Hunt, R. 1990 Basic Growth Analysis. Unwin Hyman Ltd., London.

Kawabe, T. 2006 Standard Mechanics. Shokabo Publishing Co., Ltd., Tokyo. (written in Japanese)

Milthorpe, F. L. and J. Moorby 1979 Some commonly used functions. In "An introduction to crop physiology", Cambridge University Press, Cambridge, pp. 224-227

Parks, J. R. 1982 A theory of feeding and growth of animals. Springer-Verlag, New York.

Radford, P. J. $1967 \quad$ Growth analysis formulae-their use and abuse. Crop Sci., 7: 171-175

Shimojo, M., Y. Asano, K. Ikeda, R. Ishiwaka, T. Shao, N. Ohba, H. Sato, Y. Matsufuji, M. Tobisa, Y. Yano and Y. Masuda 2002 Basic growth analysis and symmetric properties of exponential function with base e. J. Fac. Agr., Kyushu Univ., 47: 55-60

Watson, D. J. 1952 The physiological basis of variation in yield. Adv. Agron., 4: 101-145 